TARCILA BEATRIZ FERRAZ DE CAMPOS

A SUPLEMENTAÇÃO CRÔNICA COM ÁCIDO LINOLÉICO CONJUGADO PROMOVE REDUÇÃO DA MASSA ADIPOSA E COMPROMETE A SENSIBILIDADE À INSULINA NO TECIDO ADIPOSO BRANCO PERIEPIDIDIMAL 
TARCILA BEATRIZ FERRAZ DE CAMPOS

\section{A SUPLEMENTAÇÃO CRÔNICA COM ÁCIDO LINOLÉICO CONJUGADO PROMOVE REDUÇÃO DA MASSA ADIPOSA E COMPROMETE A SENSIBILIDADE À INSULINA NO TECIDO ADIPOSO BRANCO PERIEPIDIDIMAL}

Dissertação (Mestrado) apresentada ao Instituto de Ciências Biomédicas da Universidade de São Paulo, para obtenção do Título de Mestre em Ciências (Fisiologia Humana).

São Paulo 
TARCILA BEATRIZ FERRAZ DE CAMPOS

\title{
A SUPLEMENTAÇÃO CRÔNICA COM ÁCIDO LINOLÉICO CONJUGADO PROMOVE REDUÇÃO DA MASSA ADIPOSA E COMPROMETE A SENSIBILIDADE À INSULINA NO TECIDO ADIPOSO BRANCO PERIEPIDIDIMAL
}

\author{
Dissertação (Mestrado) apresentada ao \\ Instituto de Ciências Biomédicas da \\ Universidade de São Paulo, para \\ obtenção do Título de Mestre em \\ Ciências (Fisiologia Humana). \\ Área de concentração: Fisiologia Humana \\ Orientador: Prof. Dr. Fabio Bessa Lima
}

São Paulo 


\section{RESUMO}

FERRAZ DE CAMPOS, T. B. A suplementação crônica com Ácido Linoléico Conjugado promove redução da massa adiposa e compromete a sensibilidade à insulina no tecido adiposo branco periepididimal. Dissertação (Mestrado em Ciências) - Instituto de Ciência Biomédicas, Universidade de São Paulo, São Paulo, 2007.

A gordura dietética é um macronutriente importante na dieta de todos os animais. Além do seu papel como fonte de energia, a gordura dietética exerce também efeitos na expressão gênica, levando a modificações no metabolismo, crescimento e diferenciação celular. A obesidade é uma desordem crônica metabólica e nutricional, sendo que, cada vez mais há um grande interesse na descoberta de moléculas capazes de combater a obesidade. $O$ ácido linoléico conjugado (CLA) é um ácido graxo poliinsaturado natural, nutriente encontrado nos produtos da alimentação (carne bovina, aves, ovos, leite). Estudos realizados em animais indicam que o CLA possui ações contra câncer, aterogênese e DM 2. Além disso, acredita-se que este ácido graxo esteja relacionado às alterações corporais promovendo redução de gordura e aumento de massa muscular. No entanto, o mecanismo de ação pelo qual isto ocorreria ainda não foi totalmente esclarecido. O presente trabalho avaliou os efeitos da suplementação crônica com CLA em ratos Wistar machos durante 4 semanas, e teve como objetivo investigar o desenvolvimento corporal e o perfil metabólico dos animais e dos adipócitos isolados do tecido adiposos branco periepididimal. Os animais com 10 semanas de vida, foram divididos em 2 grupos: 1) grupo PUFA: suplementado com óleo de girassol; 2) PUFA+CLA 20\%: suplementado com óleo de girassol + 20\% CLA. Os animais foram acompanhados da décima a décima quarta semana de vida. Após as quatro semanas de suplementação os animais apresentaram redução no ritmo de ganho de peso corporal, acompanhado de redução da ingestão alimentar, redução da massa adiposa do TAB SC e PE e do volume celular dos adipócitos periepididimais. A menor incorporação dos substratos acetato e glicose em lipídeos, o aumento da resposta lipolítica frente ao estímulo com isoproterenol e a diminuição da expressão do fator adipogênico PPAR $\gamma$, também 
contribuíram para menor adiposidade encontrada nesses animais. Entretanto, a suplementação com CLA provocou, aumento da atividade e expressão da enzima G6PDH e do fator de transcrição ADD-1/SREBP-1. A redução de massa adiposa foi acompanhada por resistência à insulina, elevados níveis de citocinas inflamatórias e desenvolvimento de esteatose hepática sendo que esses fatores estão relacionados com o desenvolvimento de síndrome lipodistrófica em animais. Dessa forma, a efetividade do CLA em reduzir massa adiposa foi comprovada no presente estudo. Entretanto, os efeitos adversos associados com a suplementação crônica de CLA devem ser considerados.

Palavras-chave: Tecido adiposo branco. Ácido linoléico conjugado. Lipogênese. Resistência à insulina. Lipólise. 


\section{ABSTRACT}

FERRAZ DE CAMPOS, T. B. Chronic supplementation with Conjugated Linoleic Acid reduces adipose mass and impairs insulin sensitivity in periepidydimal white adipose tissue. $\mathrm{Ph}$. D. Thesis (Ms in Science) Instituto de Ciências Biomédicas, Universidade São Paulo, São Paulo, 2007.

Dietary fat is an important macronutrient in diet. Besides its role as a fuel, the dietary fat also exerts effects in gene expression, through modifications in metabolism, growth and cellular differentiation. Obesity is a chronic metabolic and nutritional disorder and there is a growing interest on the discovery of molecules capable to fight this problem. Conjugated linoleic acid (CLA) is a natural polyunsatured fatty acid found in many dietary sources, such as meat, eggs, milk. Animal studies demonstrated that CLA has properties against cancer, atherogenesis and type 2 diabetes mellitus. Besides, it is believed that this fatty acid is related to body composition alterations, promoting reduction in fat and increase in muscle mass, even though, the mechanism of action has yet to be completely elucidated. This work evaluated the effects with chronic CLA supplementation in young adults Wistar male rats for four weeks, aiming to investigate the possible changes in corporal development and metabolic profile as well as the effects in isolated adipocytes of periepidydimal white adipose tissue of these supplemented animals. Ten week-old animals were divided into two groups: 1-) PUFA group: supplemented with sunflower seed oil; 2-) PUFA+CLA 20\%: supplemented with sunflower seed oil + 20\% CLA. After a 4week follow-up, we observed a reduction of the rhythym of body weight gain, followed by diminished food intake, regression of adipose mass in subcutaneous and in periepidydimal regions, in which there was also a reduction of adipocyte volume. The findings of low incorporation of acetate and glucose substrates into lipids, elevation on the lipolytic response under isoproterenol stimulation and reduction of adipogenic factor PPAR-gamma gene expression, also contributed to the lower adiposity encountered in these animals. Interestingly, the CLA supplementation provoked a rise in the activity and expression of lipogenic enzyme G6PDH and the transcription factor ADD1/SREBP-1. This reduction in adipose mass was followed by decreased levels 
of leptin, insulin resistance, high levels of inflammatory citokines and the development of hepatic steatosis, features related to the development of lipodystrophic syndrome. Therefore, this study demonstrated the CLA effect on reduction of adipose mass, although adverse effects associated with CLA chronic supplementation must be considered.

Key words: Adipocyte metabolism. Conjugated linoleic acid. Lipogenesis. Insulin resistance. Lipolysis. 


\section{INTRODUÇÃO}

A gordura dietética é um macronutriente importante na dieta de todos os animais. Em adição ao seu papel como fonte de energia e seu efeito na composição lipídica da membrana, a gordura dietética exerce também profundos efeitos na expressão gênica, levando a modificações no metabolismo, crescimento e diferenciação celular, que se refletem em uma resposta adaptativa a mudanças na quantidade e no tipo de gordura ingerida (JUMP; CLARKE, 1999).

Em nossa alimentação, tais gorduras estão presentes e são ingeridas principalmente na forma de triacilgliceróis (TAG). Os TAG são compostos por três ácidos graxos (AG) ligados a um glicerol, mas podem existir também na forma de mono ou diacilgliceróis quando a molécula de glicerol se liga em um ou dois AG, respectivamente. Cerca de $90 \%$ dos lipídios contidos nos alimentos, assim como os lipídios dos nossos reservatórios de energia - os adipócitos - estão sob a forma de TAG (GOMES; TIRAPEGUI, 2002).

Os AG são ácidos carboxílicos com cadeia hidrocarbônica que contém de 2 a 36 átomos de carbono. Contém, em geral, sempre número par de carbonos e podem ser classificados como AG de cadeia curta (2 a 6 carbonos), média (6 a 10 carbonos) e longa (acima de 12 carbonos) (LEHNINGER et al., 2002). São armazenados como reserva energética e metabólica, funcionando como cofatores enzimáticos, detergentes, transportadores, hormônios e mensageiros celulares (GOMES; TIRAPEGUI, 2002).

Os ácidos graxos podem ser saturados ou insaturados, dependendo das duplas ligações entre os carbonos da molécula. Na ausência destas são ditos saturados. Quando possuem uma única dupla ligação, são denominados monoinsaturados (MUFAs) e se contém duas ou mais duplas ligações, poliinsaturados (PUFAs) (CURI et al., 2002). As duplas ligações têm grande importância, pois aumentam a flexibilidade da cadeia e consequentemente a fluidez das membranas biológicas. Os MUFAs estão presentes, em maior quantidade principalmente no óleo de oliva. Já os PUFAs são encontrados em 
óleos vegetais (girassol, milho, soja e algodão), óleos de peixe e em plantas oleaginosas (castanha e amêndoa).

O TAG é depositado no tecido adiposo com grande eficiência energética quando comparado à energia provinda de carboidratos, e por esse motivo o consumo de gordura está positivamente relacionado com o desenvolvimento da obesidade (CLARKE, 2000). O consumo de dietas ricas em gorduras prejudica o metabolismo de glicose, estimula uma produção anormal de insulina e causa ainda hiperinsulinemia e resistência à insulina (ESTADELLA et al., 2004).

A obesidade é uma desordem crônica metabólica e nutricional caracterizada por um excesso de tecido adiposo e apresenta sérias conseqüências para a saúde, estando relacionada com o desenvolvimento de doenças cardiovasculares, diabetes mellitus tipo 2 (DM2) e alguns tipos de câncer, e por esse motivo, cada vez mais há um grande interesse na descoberta de moléculas capazes de combater a obesidade (KOPELMAN; ALBON, 1997; SALAS-SALVADÓ; MÁRQUES-SANDOVAL; BULLÓ, 2006; POIRIER et al., 2006).

O tecido adiposo branco (TAB) possui intensa atividade metabólica e contribui notavelmente para o controle da homeostase energética do organismo podendo ser considerado um órgão central do controle metabólico. É o maior reservatório energético do organismo e é composto por adipócitos, pré-adipócitos, células do endotélio vascular, células da musculatura lisa vascular, nódulos linfáticos, células imunes e nervos. Os adipócitos são as únicas células especializadas no armazenamento de lipídeos na forma de TAG em seu citoplasma, sem que isso seja nocivo para sua integridade funcional. Essas células possuem todas as enzimas e proteínas reguladoras necessárias para sintetizar ácidos graxos (lipogênese) e estocar TAG nos períodos em que a oferta de energia é abundante e para mobilizá-los pela lipólise quando há déficit calórico. A regulação desses processos ocorre por meio de nutrientes e sinais hormonais e neurais dependendo das necessidades energéticas do indivíduo (FONSECAALANIZ et al., 2006).

Porém, o tecido adiposo não é somente um órgão de estoque de energia, mas possui também funções de órgão endócrino, produzindo uma variedade de 
moléculas biologicamente ativas que exercem tanto ações metabólicas como ações vasculares. Ultimamente, o tecido adiposo tem ganhado destaque por sua capacidade em produzir e secretar uma variedade de peptídeos bioativos, conhecidos como adipocinas que agem tanto em nível local (efeito autócrino/parácrino) como sistemicamente (efeito endócrino). Em adição a esses sinais eferentes (adipocinas), o tecido adiposo expressa numerosos receptores que permitem que ele seja alvo de sinais aferentes hormonais tradicionais e neurais (Sistema Nervoso Central - SNC). Dessa forma, além do repertório biológico necessário para estocar e liberar energia adequando-a às demandas do organismo, o tecido adiposo contém um maquinário metabólico-molecular que propicia a comunicação com órgãos distantes, em especial, o SNC. Através dessa rede interativa, o tecido adiposo está integralmente envolvido em coordenar uma variedade de ações biológicas incluindo metabolismo energético, função neuroendócrina e função imune (NADERALI, 2003; KERSHAW; FLIER, 2004).

Dentre as moléculas secretadas e que fazem o tecido adiposo ser classificado como órgão endócrino estão a leptina, a adiponectina, o fator $\alpha$ de necrose tumoral (TNF- $\alpha$ ), a interleucina-6 (IL-6) e seus receptores solúveis, a interleucina-1 $\beta$ (IL-1 $\beta$ ), a proteína quimiotática 1 de monócitos (MCP-1), o inibidor 1 do ativador do plasminogênio (PAl-1), a lipase de lipoproteínas (LPL), a apolipoproteína E, a proteína de transferência de éster de colesterol (CETP), o angiotensinogênio, o fator $\beta$ de transformação do crescimento (TGF- $\beta$ ), o fator tecidual, o fator de crescimento insulina-símile (IGF-1), os glicocorticóides, os esteróides sexuais, a proteína estimulante da acilação (ASP), a adipofilina, a adipsina, a monobutirina, a proteína agouti e prostaglandinas (FRUHBECK et al., 2001).

\footnotetext{
As adipocinas TNF- $\alpha$, IL-6, IL-1 $\beta$, MCP-1 entre outras, parecem participar na indução e manutenção do quadro inflamatório associado à obesidade. MCP-1 e outras citocinas possuem papel indispensável no recrutamento de macrófagos para o tecido adiposo, ativando processos intracelulares que promovem o desenvolvimento de resistência à insulina aumentando a propensão para o desencadeamento do DM2 (SHOELSON; LEE; GOLDFINE, 2006).
}

A leptina desempenha um importante papel na homeostase energética, estimulando, em neurônios do núcleo arqueado hipotalâmico, a expressão de neuropeptídeos ligados a mecanismos de inibição da ingestão alimentar (pro-ópio- 
melanocortina - POMC e transcrito relacionado à cocaína e anfetamina -CART) e aumentando o gasto energético total - via inervação simpática. Além disso, em outros neurônios dos mesmos núcleos, a leptina inibe a expressão de neuropeptídio Y (NPY) e peptídio agouti (AgRP) envolvidos nos mecanismos de aumento de ingestão alimentar e na redução de gasto energético (FONSECA-ALANIZ et al., 2006).

Fatores de transcrição adipogênicos incluindo o PPAR $\gamma$, ADD-1/SREBP-1, CEBP- $\alpha$, desempenham papel chave na complexa cascata transcricional que ocorre durante a adipogênese (FONSECA-ALANIZ et al., 2006). Esses fatores codificam proteínas envolvidas no desenvolvimento e na manutenção do adipócito maduro (GREGOIRE; SMAS; SUL, 1998).

O ADD/SREBP representa uma família de fatores transcricionais, que estão envolvidos na ativação de mais de 30 genes associados com síntese de colesterol, TAG e AG. O ADD1/SREBP1 está associado especificamente com síntese de AG, por estimular a expressão de muitas enzimas necessárias para o processo de lipogênese como G6PDH (HORTON; GOLDSTEIN; BROWN, 2002; KIM; SPIEGELMAN, 1996, NTAMBI; MIYAZAKI; DOBRZYN, 2004).

Diversos estudos nutricionais foram realizados a fim de determinar o efeito da gordura dietética sobre o acúmulo de gordura corporal, entretanto estes são contraditórios já que os tipos de gorduras existentes não desempenham os mesmos efeitos sobre esse parâmetro (CLARKE, 2000). Alguns estudos demonstraram que a ingestão de alimentos ricos em ácidos graxos poliinsaturados suprime a lipogênese hepática, melhora a cetogênese, e induz maior oxidação de ácidos graxos tanto no fígado como no músculo esquelético. Em conjunto, essas mudanças podem vir acompanhadas pela diminuição de deposição da gordura corporal (JUMP; CLARKE, 1999; HILL et al., 1993; COUET et al., 1997).

\section{Ácido Linoléico Conjugado (CLA)}

O ácido linoléico conjugado (CLA) é um ácido graxo poliinsaturado natural, nutriente encontrado nos produtos da alimentação diária tais como: aves, ovos e principalmente no leite e seus derivados e nas carnes bovinas. Estudos realizados em animais indicam que o CLA possui ações contra câncer, aterogênese e DM 2. 
Além disso, acredita-se que este ácido graxo esteja relacionado às alterações corporais promovendo redução de gordura e aumento de massa muscular. No entanto, o mecanismo de ação pelo qual isto ocorreria ainda não foi totalmente esclarecido. Muitos autores acreditam que a suplementação com CLA promova modificações na membrana do tecido adiposo e altere a expressão de genes relacionados com adipogênese e metabolismo do adipócito. Outros colocam que os efeitos do CLA sobre a composição corporal estejam relacionados à redução da massa adiposa e ao aumento da lipólise (LEE et al.,1998; CHOI et al.,2000; POIRIER, 2006).

Pariza e colaboradores, na década de 70, sugeriram que a carne bovina grelhada possuía um componente carcinogênico. Na busca por este componente, foi observado que, em extratos da carne bovina havia tanto componentes mutagênicos como também um componente com atividade antimutagênica e que este estava presente independente do cozimento. O extrato da carne bovina era capaz de inibir a progressão do tumor em células epiteliais de camundongos (PARIZA et al., 1985; KRITCHEVSKY, 2000).

Em $1987 \mathrm{Ha}$ e colaboradores, isolaram e caracterizaram este desconhecido componente com propriedades antimutagênicas da fração lipídica da carne e descobriram que essa fração isolada continha quatro isômeros derivados do ácido linoléico e cada um continha um sistema de dupla ligação conjugada, sendo então designados de ácidos linoléicos conjugados (CLAs).

Os CLAs compreendem uma mistura de isômeros posicionais e geométricos do ácido linoléico (ácido cis-9, cis-12 octadecadienóico), com duplas ligações conjugadas, isto é, separadas apenas por uma ligação simples carbonocarbono (Figura 1). Diferente do ácido linoléico, doze diferentes isômeros de CLA são possíveis, dependendo das duplas ligações e de sua isomeria geométrica. Essa diferença entre os isômeros é importante uma vez que os mesmos podem apresentar diferentes atividades in vivo. Os efeitos conhecidos do CLA são atribuídos principalmente a dois isômeros biologicamente ativos: cis-9, trans-11 e trans-10, cis-12 (Figura 1) (PARIZA; PARK; COOK, 2001; POIRIER et al., 2004). 
As duplas ligações do CLA podem estar localizadas nas posições C8 e C10, C9 e C11, C10 e C12 ou C11 e C13 (KELLY, 2001; LARSEN; TOUBRO; ASTRUP, 2003).

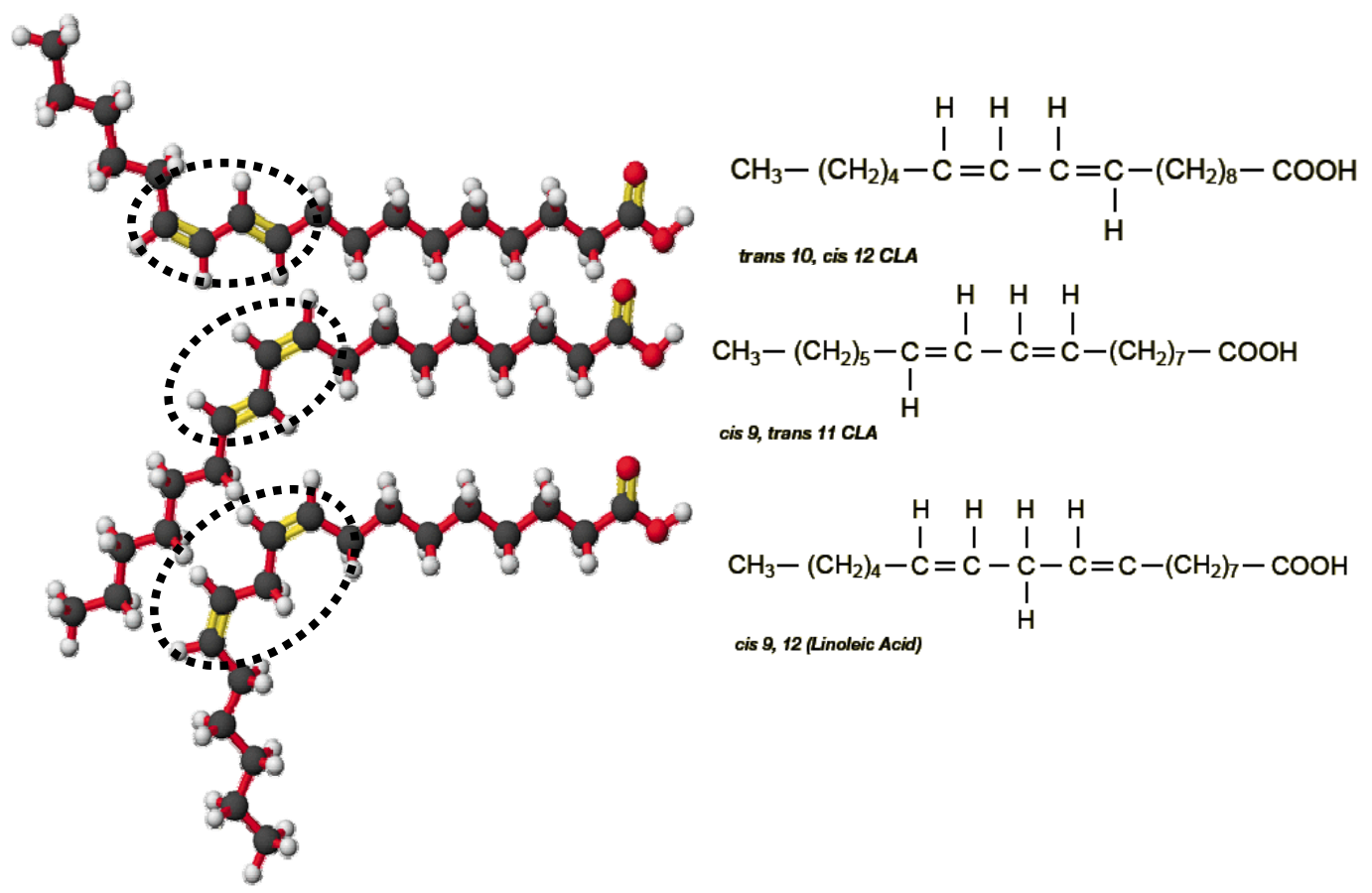

Figura 1: Estrutura dos isômeros de CLA trans-10, cis-12 (10t, 12c) e cis-9, trans-11 (9c, 11t) e do ácido linoléico. Adaptado PARIZA, PARK, COOK, 2001.

O CLA é produzido naturalmente pelas bactérias fermentativas (Butyrivibrio fibrisolvens) presentes no estômago (rúmen) de animais ruminantes e aparece em maiores concentrações em carnes, leites e seus derivados (FUNCK et al., 2006), sendo C18:2 (9c, 11t) o isômero predominante (Tabela 1). 
Tabela 1: Teor de CLA em alimentos não cozidos.

\begin{tabular}{c|c|c}
\hline Alimento & $\begin{array}{c}\text { Total CLA } \\
\text { (mg/g de gordura) }\end{array}$ & $\begin{array}{c}\text { Isômero } \\
\text { 9c, t11(\%) }\end{array}$ \\
\hline Carne bovina & 4,3 & 85 \\
Carne de cordeiro & 5,6 & 92 \\
Frango & 0,9 & 84 \\
Leite & 5,5 & 92 \\
Manteiga & 4,7 & 88 \\
Sorvete & 3,6 & 86 \\
Queijo Mussarela & 4,9 & 95 \\
Óleo de Girassol & 0,4 & 38 \\
\hline
\end{tabular}

Fonte: Adaptado de FUNCK, et al., 2001.

O CLA pode ser formado no rúmen pela biohidrogenação incompleta dos ácidos graxos poliinsaturados da dieta, principalmente o ácido linoléico, mas também endogenamente, através da dessaturação do ácido graxo C18:1 trans-11 (Ácido vacênico) por uma enzima presente no tecido adiposo e na glândula mamária chamada estearoil-coA dessaturase (SCD) ou delta-9 dessaturase (CORL et al., 2001). Como o ácido vacênico é produzido principalmente através da biohidrogenação ruminal, este processo é o grande responsável pelo fato de que as maiores fontes de CLA são produtos derivados dos ruminantes. Um grande número de espécies de bactérias do rumem produzem CLA a partir da biohidrogenação do ácido linoléico através de enzimas específicas (linoleato isomerases) (PARIZA; PARK; COOK, 2001). Normalmente a biohidrogenação acontece de forma completa, porém alguns produtos intermediários podem atravessar o rúmen e serem utilizados na síntese de lipídios no tecido mamário e adiposo (figura 2). 


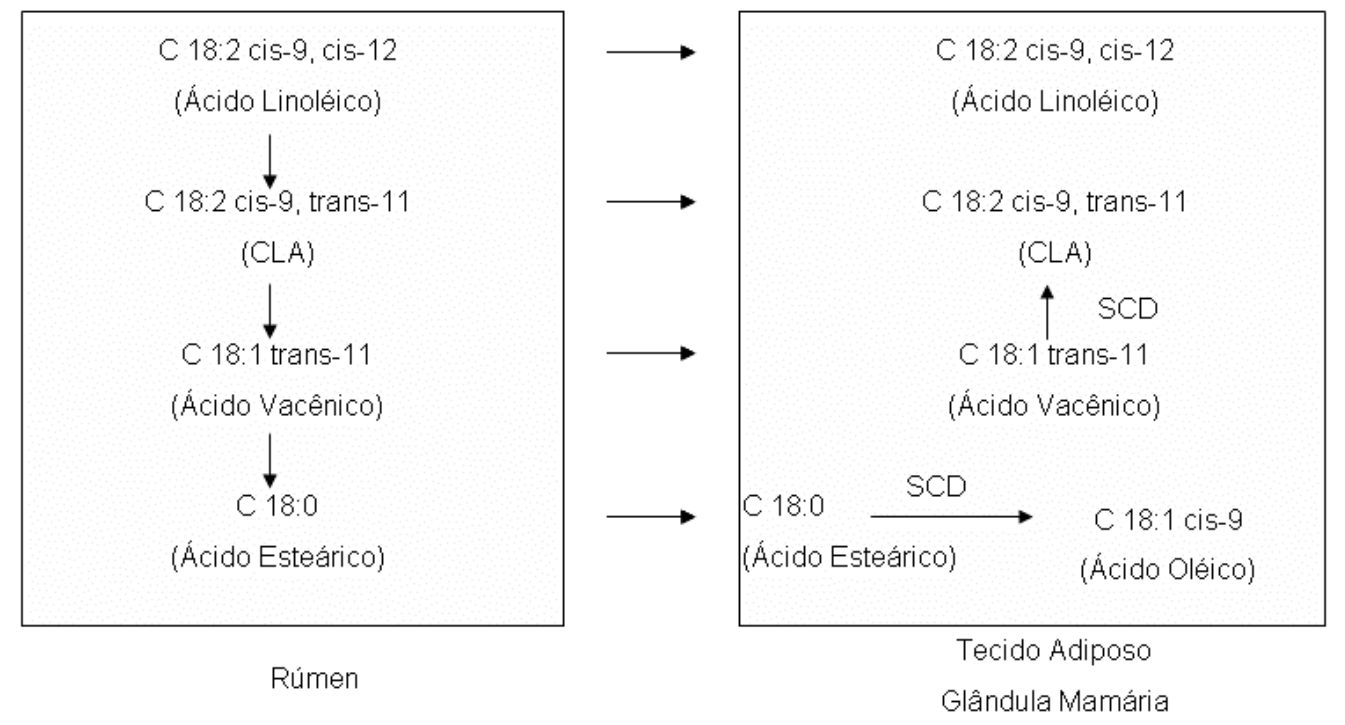

Figura 2: Via metabólica proposta para biossíntese do CLA 18:2 cis-9, trans-11. SCDEstearoil-CoA desaturase, CLA - Ácido Linoléico Conjugado. (BAUMGARD, et al., 2001).

Em humanos a produção de CLA parece ser insignificante. Herbel e colaboradores (1998) suplementaram humanos com $16 \mathrm{~g}$ de ácido linoléico, proveniente do óleo de girassol, por seis semanas e não houve diferença nos níveis plasmáticos de CLA.

Comercialmente, os isômeros de CLA podem ser produzidos por tratamentos térmicos a $\mathrm{pH}$ altos ou por hidrogenação parcial do ácido linoléico derivado principalmente do óleo de girassol (RAINER; HEISS, 2004; HAUGEN et al., 2003). A quantidade de ácido linoléico no óleo de girassol varia de extração para extração. Estes limites de variação influenciam na quantidade de ácidos linoléicos que podem ser convertidos em uma forma conjugada, e variam a potência do CLA entre $78 \%$ a $85 \%$. Entretanto, o lote típico é o de $80 \%$ conferindo a esse suplemento, conteúdo total de $39 \%$ de cada um dos dois isômeros mais ativos (18:2 c9, t11 e 18:2 t10, c12). Além destes, o produto possui também menos de $4 \%$ de ácido palmítico, menos que $4 \%$ de ácido esteárico, menos que 
$3 \%$ de ácido linoléico e 10 a $20 \%$ de ácido oléico, sendo estes são os outros ácidos naturais encontrados no óleo de girassol.

O objetivo da síntese química de CLA é produzir uma composição de CLA com atividade biológica máxima. Os métodos laboratoriais convertem o ácido linoléico principalmente nos isômeros de CLA cis-9, trans-11 e trans-10, cis-12 (PARIZA; PARK; COOK, 2001). A maior parte dos estudos que utilizam o CLA analisa o efeito da mistura de isômeros de CLA (suplementos comerciais), que contém predominantemente os isômeros CLA cis-9, trans-11 e CLA trans-10, cis-12. Uma dose de 3-4 g/dia de CLA parece produzir efeitos na composição corporal (KELLY, 2001).

Os trabalhos in vivo e in vitro realizados com CLA mostraram uma série de efeitos tanto em modelos animais, como humanos. Entre os principais efeitos destacaram-se: efeito anticarcinogênico, imunomodulação, melhora da sensibilidade à insulina, redução da pressão arterial, alterações na composição e no metabolismo do tecido adiposo (KRITCHEVSKY, 2000; HAUGEN et al., 2003; POIRIER et al., 2006).

\section{CLA e Câncer}

Existe evidência incontestável de que o CLA é um efetivo agente anticarcinogênico. O CLA pode influenciar o desenvolvimento e a progressão do câncer de três maneiras: afetando diretamente o processo da carcinogênese, reduzindo o acúmulo excessivo de gordura corporal que indiretamente aumenta o risco para câncer, e reduzindo a caquexia que está relacionada com estágios avançados do câncer (PARIZA; PARK; COOK, 1999).

O CLA foi reconhecido como agente anticarcinogênico pela primeira vez em 1987, quando pesquisadores anunciaram que haviam isolado um agente contido na carne grelhada que era capaz de inibir o câncer de epiderme em camundongos (HA; GRIMM; PARIZA, 1987). A suplementação com CLA pode, inibir ou diminuir o início de tumores induzidos quimicamente em diversas regiões do organismo de ratos e camundongos, incluindo, pele, glândula mamária e estômago.

O isômero cis-9, trans-11 parece ser por si só efetivo na neoplasia mamária quimicamente induzida. Em estudo realizado por Durgam (1997), uma suplementação com o isômero cis-9, trans-11 reduziu em $60 \%$ o crescimento de células tumorais mamárias em cultura. Os mecanismos de ação propostos para essa ação do CLA ainda não são totalmente claros e alguns estudos atribuem esses efeitos a uma redução da 
proliferação celular, do metabolismo da vitamina A (PARIZA; PARK; COOK, 2001; RAINER et al., 2004) e das prostaglandinas.

Kavanaugh e colaboradores (1999) suplementaram a dieta de camundongos com diferentes concentrações de CLA por seis semanas e verificaram uma redução na síntese de prostaglandina $E_{2}$ na epiderme dos animais o que pode levar a uma inibição do desenvolvimento tumoral. Pode-se então atribuir ao CLA um efeito anticarcinogênico a partir de uma redução na síntese de prostaglandinas. Muitos mecanismos podem justificar esse efeito do CLA. Belury (2002) demonstrou que o CLA compete com o ácido araquidônico como substrato para a ciclooxigenase, a enzima responsável pela produção de eicosanóides proinflamatórios que estão diretamente relacionados com infecção e crescimento tumoral (PARIZA, 1999).

No sistema imunológico, o CLA parece estar envolvido na proteção contra o catabolismo induzido por algumas citocinas, especialmente o fator de necrose tumoral a (TNF- $\alpha$ ) que está relacionado com o desenvolvimento da caquexia associada ao câncer. O CLA reduz os efeitos catabólicos adversos da estimulação do sistema imune, podendo ser utilizado em conjunto nos tratamentos de quimioterapia. Uma dieta suplementada com $0,5 \%$ de CLA demonstrou efeitos protetores contra o desenvolvimento de caquexia associada ao TNF- a (RAINER; HEISS, 2004).

Outro mecanismo que pode ser atribuído ao efeito do CLA é a redução da proliferação celular que tem sido observada em cultura de células e em modelos animais. Uma possível explicação para esse efeito pode ser o aumento do processo de apoptose mediado pelo CLA. Bergamo, e colaboradores (2004), atribuíram ao CLA um mecanismo de atividade anticancerígena, envolvendo produção de espécies reativas de oxigênio, que levam a ativação de uma enzima denominada de caspase-3, considerada enzima chave no processo de apoptose. Outros autores também relataram aumento no processo de apoptose no tecido mamário, fígado e tecido adiposo (HAUGEN et al., 2003; HARGRAVE, 2004). Por esses efeitos, o CLA foi reconhecido em 1996, pela Academia Nacional de 
Ciências dos Estados Unidos, como o único ácido graxo capaz de inibir carcinogênese em modelos de animais experimentais.

Outra maneira indireta do CLA interferir no bloqueio ao desenvolvimento da carcinogênese é através dos seus efeitos na redução de gordura corporal, já que um excesso de tecido adiposo contribui como um fator de risco no desenvolvimento de câncer (PARIZA; PARK; COOK, 1999).

\section{CLA, Resistência à Insulina e Lipodistrofia}

Sob condições onde o TAB é incapaz de estocar TAG, os ácidos graxos livres (AGLs) permanecem elevados no plasma e são depositados em outros tecidos periféricos como fígado e músculo. Essa condição é conhecida como lipodistrofia, e está fortemente correlacionada com resistência à insulina (BROWN; MCINTOSH, 2003). A resistência à insulina, definida como a condição de reduzida sensibilidade à ação da insulina, também pode elevar a secreção desse hormônio para valores acima do normal, ocasionando, dessa forma, a exaustão das células B pancreáticas (FUJIMOTO, 2000).

Alguns estudos em modelos animais demonstraram que o isômero de CLA trans 10 , cis 12 , leva a um estado de resistência à insulina, e dificulta a captação de glicose e AG pelos adipócitos, resultando em hiperglicemia e hiperlipidemia (CLEMENT et al., 2002; TSUBOYAMA-KASAOKA et al., 2000).

A resistência à insulina encontrada na obesidade, é acompanhada por efeitos em outros sistemas. Dessa forma um aumento do acúmulo de gordura pode levar a mudanças no metabolismo de glicose e lipídeos como também em outros sistemas incluindo pressão arterial. Entretanto, a deficiência de tecido adiposo (lipodistrofia), total ou parcial, também é acompanhada de resistência à insulina e alta incidência de DM2 (GANDA, 2000).

A lipodistrofia altera a distribuição dos $A G$ entre adipócitos, músculo e fígado, promovendo um acúmulo de TAG em outros tecidos, como por exemplo, o fígado (esteatose hepática), e esse acúmulo, a longo prazo, pode levar a uma sinalização e ação insulínicas deficientes nesses tecidos (KIM et al., 2000).

Alguns estudos associaram a suplementação crônica com CLA ao desenvolvimento de esteatose hepática em modelos animais e relacionaram este efeito, com os altos níveis de insulina detectados nesses animais, já que quando 
os níveis de insulina foram normalizados o quadro de esteatose hepática foi revertido (TSUBOYAMA-KASAOKA et al., 2000; GAVRILOVA et al., 2000).

\section{CLA e Obesidade}

O CLA demonstrou na literatura, possíveis efeitos anti-obesidade principalmente em modelos animais. Em 1997, Pariza e colaboradores, demonstraram pela primeira vez que a suplementação com CLA 0.5\% de CLA em camundongos de 6 semanas, suplementados por um mês, foi capaz de promover uma redução da massa adiposa. Este feito foi atribuido a um possível aumento da lipólise junto com uma melhora na oxidação de ácidos graxos tanto nas células adiposas como no tecido muscular. Ratos Sprague-Dawley, que receberam uma mistura de isômeros de CLA a 3\% na dieta por 3 semanas, apresentaram, uma redução de $27 \%$ na gordura corporal e um aumento de $11 \%$ na massa magra corporal comparada com os valores correspondentes dos animais que foram alimentados com a dieta controle (PARIZA; PARK; COOK, 2001).

Rahman e colaboradores (2001) suplementaram ratos Otsuka Long Evans Tokushima Fatty (OLETF-modelo animal para obesidade e diabetes mellitus não insulino dependente) com CLA (1\%) durante 4 semanas e observaram redução nos depósitos adiposos das regiões peri-renal, epididimal e omental. Já em ratos obesos $(Z D F)$ a suplementação com CLA causou um aumento de $15 \%$ tanto na gordura inguinal, como na gordura retroperitoneal, demonstrando que os efeitos do CLA variam de acordo com o genótipo do animal (KELLEY; ERICKSON, 2003).

Os mecanismos propostos para esses processos de redução da gordura corporal são: aumento da lipólise, aumento da oxidação de ácidos graxos ou redução da captação de ácidos graxos pelos adipócitos (BHATTACHARYA et al., 2006). Em cultura de células da linhagem 3T3-L1 de adipócitos, contendo o isômero trans-10, cis-12 (0,5\%), houve uma inibição direta da enzima lipase de lipoproteína (LPL) e aumento significativo da concentração de glicerol no meio de cultura, fator esse que pode ser considerado como um indicativo do aumento da lipólise. O aumento na lipólise pode estar acoplado a um aumento da oxidação de 
ácidos graxos pelas células musculares e adiposas, e isso ocorre devido ao fato de que o CLA melhora a atividade da enzima carnitina-palmitoiltransferase (CPT) em ratos, que é o passo limitante para a oxidação de ácidos graxos. Entretanto, a maior parte dos estudos aponta que esses efeitos se devem principalmente da ação do isômero trans-10, cis-12 (PARIZA; PARK; COOK, 2001).

O aumento no tamanho do adipócito é conseqüente a um ganho de massa de gordura corporal, enquanto a redução da massa gorda conduz a redução no tamanho das células adiposas (BELURY, 2002). Muitos estudos demonstraram um maior efeito do CLA na redução do tamanho dos adipócitos. Fêmeas de camundongos alimentados com 1\% de CLA apresentaram uma quantidade maior de adipócitos menores quando comparados com o grupo controle. Em ratos Sprague-Dawley, a dieta enriquecida com CLA reduziu o peso do coxim adiposo visceral devido a uma diminuição do tamanho dos adipócitos e não pela redução do número de células. Os autores atribuem esses efeitos a mudanças metabólicas como diminuição da lipogênese e aumento da lipólise (TSUBOYAMA-KASAOKA et al., 2000; AZAIN et al., 2000).

O efeito inibitório do CLA na lipogênese está correlacionado com a inibição da enzima LPL, como foi descrito em estudos in vitro (PARK et al., 1997). Além disso, foram descritos efeitos como redução na quantidade de RNAm de enzimas lipogênicas, como a ácido graxo sintase (FAS) e acetil-coA carboxilase (ACC), em camundongos fêmeas (C57BL/6J) alimentadas durante 5 meses com uma dieta contendo CLA a 1\%. A expressão dessas enzimas é regulada por fatores de transcrição como proteína 1c ligadora do elemento regulado por esteróis (SREBP1) e o receptor gama ativado por proliferadores de peroxissomas (PPAR- $\gamma$ ) e estes se encontram menos expressos em animais suplementados com CLA (TSUBOYAMA-KASAOKA et al., 2000; TAKAHASHI et al., 2002). Esses dados sugerem que o CLA diminui o conteúdo de TAG no adipócito por reduzir a síntese, a captação e a esterificação dos ácidos graxos pelos adipócitos.

Outra possibilidade em relação à diminuição na deposição de gordura corporal seria um aumento do gasto energético (WEST et al., 2001). Proteínas desacopladoras (Uncoupling proteins - UCP-2 e UCP-3) regulam o gasto 
energético, e induzem termogênese a partir da dieta. A UCP-2 é altamente expressa no músculo esquelético e no tecido adiposo e o CLA aumenta a expressão da UCP-2 no tecido adiposo, sendo esse um mecanismo para o aumento do gasto energético demonstrado em alguns estudos (EVANS et al., 2001; CHOI et al., 2004; POIRIER et al., 2005).

O CLA possui também efeitos nos pré-adipócitos, diminuindo sua proliferação e diferenciação, e pode possivelmente interferir nos processos de expansão dos depósitos de gordura. A diferenciação do pré-adipócito é mediada por uma série de mudanças programadas na expressão de proteínas específicas do adipócito, reguladas por fatores de transcrição como CCAATT/ enhancer binding protein- $\alpha$ (C/EBP- $\alpha)$ e o PPAR $\gamma$. O CLA é tido como um possível ligante para PPAR $\gamma$, afetando o desenvolvimento do tecido adiposo e a expressão gênica in vitro (DOMENEGHINI; DIGIANCAMILLO; CORINO, 2006). Os PPARs possuem um papel central na adipogênese, no metabolismo de glicose e de lipídeos. As principais isoformas do PPAR são a $\alpha$ e a $\gamma$, sendo que o PPAR $\alpha$ é altamente expresso no fígado e o PPAR $\gamma$ é predominantemente expresso no tecido adiposo e, em menor quantidade no fígado, e seus principais ligantes incluem as tiazolidinedionas (TZDs, um grupo de drogas sensibilizadoras de insulina), as prostaglandinas e derivados do ácido linoléico. A ativação do PPAR promove adipogênese, melhora a sensibilidade à insulina e diminui a concentração de AGL circulante. Com isso, derivados dos ácidos graxos livres parecem ser ativadores do sistema PPAR e, portanto, é claro que a gordura dietética pode diretamente influenciar no metabolismo glicídico. Dão suporte a este conceito, estudos demonstrando que a alteração na quantidade e no tipo de gordura dietética pode influenciar na homeostase metabólica da glicose (PRINS, 2002).

Foi documentado que o CLA (principalmente, o isômero trans-10, cis-12) está envolvido nessa regulação, sendo que o CLA pode suprimir a expressão e atividade do PPAR- $\gamma$. Estudos in vivo e in vitro demonstram que o trans-10, cis-12 possui um papel delipidativo e esse efeito acontece logo nos primeiros dias de suplementação (PARIZA; PARK; COOK, 2001). 
Outro processo importante que pode estar associado com reduções na deposição de gordura corporal induzida pela suplementação com CLA é a apoptose. Estudos demonstram que o CLA está associado com um aumento da morte celular programada (apoptose) nas células do tecido adiposo branco em camundongos e em cultura de pré-adipócitos. Um potente mecanismo que leva a apoptose e está relacionado com o CLA envolve o TNF- $\alpha$. O aumento de CLA na dieta de fêmeas de camundongos elevou os níveis de TNF- $\alpha$ e de seu RNAm no tecido adiposo contribuindo para $\mathrm{O}$ aumento nas taxas de apoptose (TSUBOYAMA-KASAOKA et al., 2000; POIRIER et al., 2006; DOMENEGHINI; DIGIANCAMILLO; CORINO, 2006).

Assim, na figura 3, está representado um esquema resumindo as diversas formas de como principalmente o isômero trans-10, cis 12 pode afetar mudanças na composição corporal.

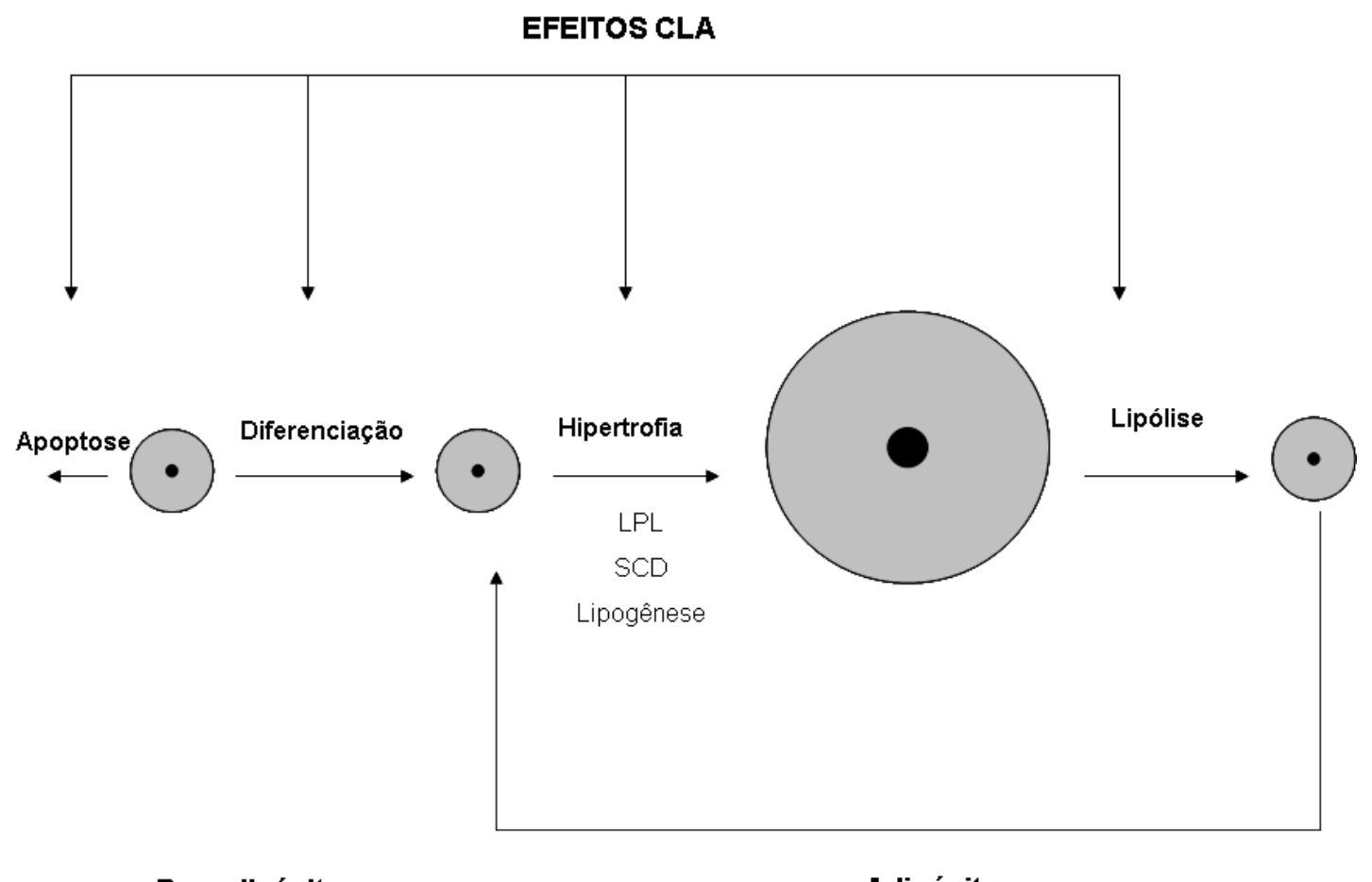

Pre-adipócito

Adipócito

Figura 3: Esquema representando os efeitos do CLA nos adipócitos e pré-adipócitos. CLA Ácido linoléico conjugado; LPL -Lipase de liporpoteína; SCD - Estearoil-CoA desaturase. Os sinais + (estimula) e - (inibe), representam os efeitos do CLA sobre os eventos mencionados. (PARIZA; PARK; COOK, 2001-Adaptado). 
Os resultados dos estudos clínicos com humanos sobre os efeitos do CLA na composição e peso corporal ainda são inconsistentes. A redução do peso corporal foi observada em pacientes com DM2 que receberam suplementos de 6 g/dia contendo $39 \%$ trans -10 , cis- 12 e $37 \%$ cis- 9 , trans -11 . No entanto, em outro estudo realizado em humanos não demonstrou efeito no peso corporal em homens e mulheres saudáveis obesos e não-obesos (WANG; JONES, 2004).

O tratamento com CLA (3,4\%-6,8\%), durante 3 meses reduziu a massa de tecido adiposo em humanos adultos obesos e com sobrepeso (BLANKSON et al., 2000). Brown e colaboradores (2001) conduziram experimentos utilizando culturas primárias de células do estroma vascular de humanos, e verificaram uma diminuição no conteúdo de TAG com doses de CLA variando de 1-10 $\mu \mathrm{mol} / \mathrm{L}$, e uma redução na incorporação de glicose $\left[{ }^{14} \mathrm{C}\right]$ nos lipídios totais, sendo que a maior dose de trans-10, cis-12 (30 $\mu \mathrm{mol} / \mathrm{L})$, levou a uma redução de $80 \%$, porém nenhuma alteração foi observada nos processos de lipólise, correlacionando o efeito anti-obesidade do CLA em humanos a uma inibição da lipogênese, principalmente mediada pelo isômero trans-10, cis-12.

O objetivo dos estudos com CLA em humanos é a diminuição dos estoques de gordura já existentes, porém, a maior parte dos estudos em animais é realizada na fase de crescimento, demonstrando um efeito dessa suplementação na formação do tecido adiposo. Dessa forma, as condutas experimentais variando itens como idade, tipo e estado metabólico do modelo animal, assim como quantidade, tipo de isômero de CLA, e duração do tratamento desempenham um papel importante no modo pelo qual o CLA afeta a composição corporal. Estudos em animais adultos não reproduzem os mesmos resultados demonstrados em animais em fase de crescimento e, portanto tornam-se necessários mais estudos que demonstrem como o CLA pode interferir tanto na composição corporal como no perfil metabólico de ratos na fase adulta, além de garantir se esses efeitos não estão sendo acompanhados de respostas prejudiciais para o organismo. 


\section{CONCLUSÕES}

A suplementação crônica com CLA em ratos Wistar na fase adulta promoveu redução do peso corporal acompanhado, de reduzida ingestão alimentar o que contribuiu para o menor ganho de massa adiposa desses animais nos territórios de TAB SC e PE.

A reduzida massa do coxim adiposo PE pode ser explicado: pelo menor volume celular apresentado pelos animais suplementados com CLA; pela menor incorporação de glicose e acetato em lipídeos; pelo aumento da resposta lipolítica estimulada por isoproterenol; e menor quantidade de RNAm do PPAR $\gamma$.

Essa perda de massa gorda está relacionada com prejuízos na resposta metabólica sistêmica (desenvolvimento de resistência à insulina) e na dos adipócitos isolados do TAB da região PE que apresentam diminuição na captação e oxidação de glicose.

Muitos desses processos podem estar relacionados com o quadro lipodistrófico associado à suplementação com CLA, que nesses animais foi caracterizado por baixos níveis de leptina, altos níveis de insulina, esteatose hepática e desenvolvimento de um perfil inflamatório.

Em resposta a esse prejuízo metabólico a suplementação com CLA resultou em aumento da expressão do fator adipogênico ADD1/SREBP-1 e da expressão e atividade da enzima G6PDH, funcionando como um efeito protetor e compensatório no processo de delipidação do tecido adiposo causado pela suplementação com CLA.

Dessa forma, a efetividade do CLA em reduzir massa adiposa foi comprovada no presente estudo. Entretanto, os efeitos adversos associados com a suplementação crônica com CLA devem ser considerados. 


\section{REFERÊNCIAS BIBLIOGRÁFICAS}

AZAIN, M. J.; HAUSMAN, D. B.; SISK, M. B.; FLATT, W. B.; JEWELL, D. E. Dietary Conjugated Linoleic Acid Reduces Rat Adipose Tissue Cell Size Rather than Cell Number. Journal of Nutrition, v. 130, p. 1548-1554, 2000.

BASKIN, D.G.; LATTEMANN, D.F.; SEELEY, R.J.; WOODS, S.C.; PORTE, D.; SHWARTZ, M.W. Insulin and leptin: dual adiposity signals to the brain for the regulation of food intake and body weight. Brain Research, v. 848, n.1-2, p. 114123, 1999.

BAUMGARD, L. H.; SANGSTER, J. K.; BAUMAN, D. E. Milk Fat Synthesis in Dairy Cows Is Progressively Reduced by Increasing Supplemental Amounts of trans-10, cis-12 Conjugated Linoleic Acid (CLA). The Journal of nutrition, v. 131, p. 17641769, 2001.

BELURY, M. A. Dietary conjugated linoleic acid in health: physiological effects and mechanisms of action. Annual Review of Nutrition, v. 22, p. 505-531, 2002.

BELURY, M.A.; KEMPA-STECZKO, A. Conjugated linoleic acid modulates hepatic lipid composition in mice. Lipids, v. 32, n. 2, p. 199-204, 1997.

BERGAMO, P.; LUONGO, D.; ROSSI, M. Conjugated linoleic acid - mediated apoptosis in Jurkat $T$ cells involves the production of reactive oxygen species. Cellular Physiology and Biochemistry, v. 14, n. 1-2, 2004.

BERGMAYER, H. U.; BERNT, E. D. D-glucose determination with hexokinase and glucose-6-phosphatase dehydrogenase. In: BERGMEYER, H. U. (Ed.). Methods of Enzymatic Analysis. Londres: Academic Press, p. 1196-1201, 1974.

BHATTACHARYA, A.; BANU, J.; RAHMAN, M.; CAUSEY, J.; FERNANDES, G. Biological effects of conjugated linoleic acids in health and disease. Journal of Nutrition Biochemistry, v. 17, p., 789-810, 2006.

BLANKSON, H.; STAKKESTAD, J. A.; FAGERTUM, H.; THOM, E.; WADSTEIN, J.; GUDMUNDSEN, O. Conjugated Linoleic Acid Reduces Body Fat Mass in Overweight and Obese Humans. Journal of Nutrition, v. 130, p. 2943-2948, 2000.

BONORA, E.; MOGHETTI, P.; ZANCANARO, C.; CIGOLINI, M.; QUERENA, M.; CACCIATORI, V.; CORGNATI, A.; MUGEO, M. Estimates of in vivo insulin action in man: comparison of insulin tolerance tests with euglycemic and hyperglycemic glucose clamp studies. Journal of Clinical Endocrinology \& Metabolism, v. 68, p. 374-378, 1989. 
BONORA, E.; TARGHER, G.; ALBERICHE, M.; BONADONNA, R.C.; SAGGIANI, F.; ZENERE, M. B.; MONAUNI, T.; MUGGEO, M. Homeostasis model assessment closely mirrors the glucose clamp technique in the assessment of insulin sensitivity. Diabetes Care, v. 23, p. 57-63, 2000.

De acordo com: ASSOCIAÇÃO BRASILEIRA DE NORMA TÉCNICAS. NBR 6023: Informação e documentação: referências: elaboração. Rio de Janeiro, 2002

desaturation activities in vitro. Lipids, v. 34, n. 9, p. 965-969, 1999.

BROWN, J. M.; HALVORSEN, Y. D.; LEA-CURRIE, Y. R.; GEIGERMAN, C.; McINTOSH. Trans-10, cis-12, but not cis-9, trans-11, conjugated linoleic acid attenuates lipogenesis in primary cultures of stromal vascular cells from human adipose tissue. Journal of Nutrition, v. 131, p. 2316, 2321, 2001.

BROWN, J.M.; McINTOSH, M.K. Conjugated Linoleic Acid in Humans: Regulation of Adiposity and Insulin Sensitivity. The American Society for Nutritional Sciences, V.133, p. 3041-3046, 2003.

BROWN, J.M.; BOYSEN, M.S.; CHUNG, S.; FABIYI, O.; MORRISON, R. F.; MANDRUPE, S.; McINTOSH, M.K. Conjugated Linoleic Acid Induces Human Adipocyte Delipidation. J. Biol. Chem., v. 279, n. 25, p. 26735-26747, 2004

CAO, Z. P.; WANG, F.; CAO, R.; ZHANG, W. B.; GAO, S. B. Intracerebroventricular administration of conjugated linoleic acid (CLA) inhibits food intake by decreasing gene expression of NPY and AgRP. Neurosci. Lett., v. 418, n. 3, p. 217-221, 2007.

CARVALHEIRA, J. B. C.; SAAD, M. J. A. Doenças associadas à resistência à insulina/hiperinsulinemia, não incluídas na síndrome metabólica. Arq. Bras. Edocrinol. Metab., v. 5, n. 2, p. 360-367, 2006.

CHOI, J. S.; JUNG, M. H.; PARK, S. H.; SONG, J. Effect of conjugated linoleic acid isomers on insulin resistance an mRNA levels of genes regulating energy metabolism in high-fat-fed rats. Nutrition, v. 20, p. 1008-1017, 2004.

CHOI, Y.; KIM, C-Y.; HAN, B-Y.; PARK, Y.; PARIZA, M. W.; NTAMBI, J. M. The trans-10,cis-12 Isomer of Conjugated Linoleic Acid Downregulates Stearoyl-CoA Desaturase 1 Gene Expression in 3T3-L1 Adipocytes. Journal of Nutrition, v. 130, p. 1920-1924, 2000.

CHOI, Y.; PARK, Y.; STORKSON, J.M.; PARIZA, M.W.; NTAMBI, J.M. Inhibition of stearoyl-CoA desaturase activity by the cis-9,trans-11 isomer and the trans-10,cis12 isomer of conjugated linoleic acid in MDA-MB-231 and MCF-7 human breast cancer cells. Biochemical and Biophysical Research Communications, v. 294, n. 4, p. 785, 790, 2002. 
CHUNG, S.; BROWN, J.M.; POVO, J. N.; HOPKINS, R.; MCINTOSH, M. K. Conjugated Linoleic Acid Promotes Human Adipocyte Insulin Resistance through NF $\kappa$ B-dependent Cytokine Production. J. Biol. Chem., V. 280, n. 46, p. 3844538456, 2005.

CLARKE, S. D.; Polyunsaturated fatty acid regulation of gene transcption: a mechanism to improve energy balance and insulin resistance. British Journal of Nutrition, v.83, n. 1, 2000, 59-66.

CLEMENT, L.; POIRIER, H.; NIOT, I.; BOCHER, V.; GUERRE-MILO, M.; KRIEF, S.; STAELS, B.; BESNARD, P. Dietary trans-10,cis-12 conjugated linoleic acid induces hyperinsulinemia and fatty liver in the mouse. Journal of Lipid Research. v. 43, p. 1400-1409, 2002.

COHEN, P. et al. Role for Stearoyl-CoA Desaturase-1 in Leptin-Mediated Weight Loss. Science, v. 297, n. 5579, p. 240-243, 2002.

CORL, B. A.; BAUMGARD, L. H.; DAWYER, D. A.; GRIINARI, J. M.; PHILLIPS, B. S.; BAUMAN, D. E. The role of $\Delta-9$ desaturase in the production of cis-9, trans- 11 . The Journal of Nutritional Biochemistry, v. 12, n. 11, p. 622-630, 2001.

COUET, C.; DELARUE, J.; RITZ, P.; ANTOINE, J.M.; LAMISSE, F. Effect of dietary fish oil on body fat mass and basal fat oxidation in healthy adults. Int. $J$. Obes. Relat. Metab. Disord.v. 21, n. 8, p. 637-643, 1997.

CURI, R; POMPÉIA, C, MIYASAKA, C.K.; PROCÓPIO, J. Entendendo a Gordura: os ácidos graxos. São Paulo: Editora Manole,2002.

DELANY, J.P.; BLOHM, F.; TRUETT, A. A.; SCIMECA, J. A.; WEST, D. B. Conjugated linoleic acid rapidly reduces body fat content in mice without affecting energy intake. American Physiology Society, p. 1172-1179, 1999.

DELANY, J.P.; WEST, D.B. Changes in Body Composition with Conjugated Linoleic Acid. American College of Nutrition, v. 19, n. 4, p. 487-493, 2000.

DIGIROLAMO, M.; MEDLINGER, S.; FERTIG, W.A. A simple method to determine fat cell size and number in four mammalian species. Am. J. Physiol, v. 221, n. 3, p. 850-888, 1971.

DOLE, V.P.; MEIRNETZ, H. Microdetermination of long chain fatty acids in plasma and tissues. J.Biol.Chem, v. 235, p.2595-2599, 1960.

DOMENEGHINI, C.; DI GIANCAMILLO, A.; CORINO, C. Conjugated linoleic acids (CLAs) and white adipose tissue: how both in vitro an in vivo studies tell the story of a relationship. Histol Histopathol, v. 21, p. 663-672, 2006. 
DRUCKER, D.J. The Glucagon-Like Peptides. Endocrinology, v. 142, n. 2, p. 521-527, 2001.

DRUCKER, D.J. Biological actions and therapeutic potential of the glucagon-like peptides. Gastroenterology, v. 122, n. 2, p. 531-544, 2002.

DURGAM, V. R.; FERNANDES, G. The growth inhibitory effect of conjugated linoleic acid on MCF-7 cells is related to estrogen response system. Cancer Letters, v. 166, n. 2, 1997

ESTADELLA, D., et al. Effect of palatable hyperlipidic diet on lipid metabolism of sedentary and exercised rats. Nutrition, v. 20, p. 218-224, 2004.

EVANS, E. M.; BROWN, J. M.; McINTOSH, M. K. Isomer-specific effects of conjugated linoleic acid (CLA) on adiposity and lipid metabolism. Journal of Nutritional Biochemistry, v. 13, p. 508-516, 2002.

EVANS, E. M.; PARK, Y.; PARIZA, M.; CURTIS, L.; KLUEBER, B.; McINTOSH, M. Trans-10,Cis-12 conjugated linoleic acid reduces triglyceride content while differentially affecting peroxisome proliferator activated receptor $\mathrm{y} 2$ and aP2 expression in 3T3-L1 preadipocytes. Lipids, v. 36, n. 11, p. 1223-1232, 2001.

FAULCONNIER, Y.; ARNAL, M.; MIRAND, P.P.; CHARDIGNY, J.; CHILLIARD, Y. Isomers of conjugated linoleic acid decrease plasma lipids and stimulate adipose tissue lipogenesis without changing adipose weight in post-prandial adult sedentary or trained Wistar rat. The Journal of Nutritional Biochemistry, v. 15, n. 12, p. 741-748, 2004.

FONSECA-ALANIZ, M. H.; TAKADA, J.; ALONSO-VALE, M. I. C.; LIMA, F. B. O tecido adiposo como centro regulador do metabolismo. Arquivos Brasileiros de Endocrinologia e Metabologia, v. 50, n. 2, p. 216-229, 2006.

FRIEDWALD, W. T.; LEVI, R. I.; FREDRICKSON, D. J. Estimation of the concentration of low density lipoprotein cholesterol in plasma without use of the ultracentrifuge. Clin. Chem., v.18, n. 6, p. 499-452, 1972.

FRUBECK, G.; GÓMEZ-AMBROSI, J.; MURUZÁBAL, F. J.; BURREL, M. A. The adipocyte: a model for integration of endocrine and metabolism regulation. Am. J. Phisiol. Endocrinol. Metab., v. 43, n. 6, p. E827-847, 2001.

FUJIMOTO, W.Y. The importance of insulin resistance in the pathogenesis of type 2 diabetes mellitus. The American Journal of Medicine., v. 108, n. 6, p. 9-14, 2000.

FUNCK, G. L.; BARRERA - ARELLANO, D.; BLOCK, M. J. Ácido linoléico conjugado (CLA) e sua relação com doença cardiovascular e os fatores de risco associados. Archivos Latinoamericanos de Nutrición, v. 56, n. 2, p, 1-11, 2006. 
GANDA, O.P. Lipoatrophy, lipodystrophy, and insulin resistance. Ann Intern Med., v. 15 , p. 263-264, 2000.

GAVINO, V. C.; GAVINO, G.; LEBLANC, M-J.; TUCHWEBER, B. An Isomeric Mixture of Conjugated Linoleic Acids But Not Pure cis-9,trans-11-Octadecadienoic Acid Affects Body Weight Gain and Plasma Lipids in Hamsters. Journal of Nutrition, v. 130, p. 27-29, 2000.

GAVRILOVA, O.; MARCUS-SAMUELS, B.; SHULMAN, G.I.; CASTLE, A.L.; VINSON, C.; EKHAUS, M.; REITMAN, M.L. Surgical implantation of adipose tissue reverses diabetes in lipoatrophic mice. J. Clin. Invest., v. 105, n. 3, p. 271-278, 2000.

GOMES, M. R. G.; TIRAPEGUI, J. Lipídios. In: Nutrição: fundamentos e aspectos atuais. São Paulo: Editora Atheneu, 2002, p. 49-50.

HA, Y. L.; GRIMM, N. K.; PARIZA, M. W. Anticarcinogens from fried ground beef: heat-altered derivatives of linoleic acid. Carcinogenesis, v.8, n.12, p. 1881-1887, 1987.

HABER, E. P.; CURI, R.; CARVALHO, C. R. O.; CARPINELLI, A. R.; Secreção de insulina: Efeito autócrino da insulina e modulação por ácidos graxos. Arq. Bras. Endocrinol. Metab., v. 45, n. 3, 2001.

HARGRAVE, M. K.; MEYER, B. J.; LI, C.; AZAIN, M. J.; BAILE, C. A.; MINER, J. L. Influence of dietary conjugated linoleic acid and fat source on body fat and apoptosis in mice. Obesity Research, v. 12, p. 1435-1444, 2004.

HAUGEN, M.; VIKSE, R.; ALEXANDER, J. CLA (Conjugated Linoleic acid) and adverse health effects: a review of the relevant literature. The Norwegian Institute for Public Health, v. 33, p. 49-60, 2003.

HERBEL, B. K.; MCGUIRE, M. K.; MCGUIRE, M. A.; SHULTZ, T. D. Safflower oil consumption does not increase plasma conjugated linoleic acid concentrations in humans. American Journal of Clinical Nutrition, v. 67, p. 332-337, 1998.

HILL, J.O.; PETERS, J.C.; LIN, D.; YAKUBU, F.; GREENE, H.; SWIFT, L. Lipod accumulation and body fat distribution is influenced by type of dietary fat fed to rats. Int. J. Obes., v. 17, p. 223-236; 1993.

HONNOR, R. C; DHILLON, G. S.; LONDOS, C. cAMP-dependent protein kinase and lipolysis in rat adipocytes. Cell prepration, manipulation, and predictability in behavior. J Biol Chem, v. 200, p. 15122-15129, 1985. 
HORTON, J.D.; GOLDSTEIN, J.L.; BROWN, M.S. SREBPs: activators of the complete program of cholesterol and fatty acid synthesis in the liver. J. Clin. Invest., v. 109, n. 9, p. 1125-1131, 2002.

HOTAMISLIGIL, G.S.; SHARGILL, N.S.; SPIEGELMAN, B.M. Adipose expression of tumor necrosis factor-alpha: direct role in obesity-linked insulin resistance. Science, v. 259, n. 5091, p. 87-91, 1993.

HOUSEKNECHT, K. L.; HEUVEL, J. P. V.; MOYA-CAMARENA, S. Y.; PORTOCARRERO, C. P.; PECK, L. W.; NICKEL, K. P.; BELURY, M. A. Dietary linoleic conjugated acid normalizes impaired glucose tolerance in the Zucker diabetic fatty fa/fa rat. Biochemical and Biophysical Research Communications, v. 244, n. 3, p. 678-682, 1998.

IDE, T. Interaction of fish oil and conjugated linoleic acid in affecting hepatic activity of lipogenic enzymes and gene expression in liver and adipose tissue. Diabetes, v. 54, p. 412-423, 2005.

INOUE, N.; NAGAO, K.; HIRATA, J.; WANG Y-M.; YANAGITA, T. Conjugated linoleic acid prevents the development of essential hypertension in spontaneously hypertensive rats. Biochemical and Biophysical Research Communications, v. 323, n. 2, p. 679-684, 2004.

JUMP, D. B.; CLARKE, S. D. Regulation of gene expression by dietary fat. Annual Review of Nutrition, v. 19, p. 63-90, 1999.

KAVANAUGH, C. J.; LIU, K-L.; BELURY, M. A. Effect of Dietary Conjugated Linoleic Acid on Phorbol Ester-Induced $\mathrm{PGE}_{2}$ Production and Hyperplasia in Mouse Epidermis. Nutrition and Cancer, v. 33, n. 2, 1999.

KANG, K.; LIU, W.; ALBRIGHT, K.J.; PARK, Y.; PARIZA, M.W. trans-10,cis-12 CLA inhibits differentiation of 3T3-L1 adipocytes and decreases PPARY expression. Biochemical and Biophysical Research Communications, v. 303, n. 3, p. 795-799, 2003.

KELLEY, D. S.; ERICKSON, K. L. Modulation of body composition and immune cell functions by conjugated linoleic acid in humans and animal models: Benefits vs. risks. Lipids, v. 38, n. 4, p. 377-386, 2003.

KELLY, G. S. Conjugated linoleic acid: a review. Altern. Med. Rev., v. 6, n.4, p. 367-382, 2001.

KERSHAW, E. E., FLIER, J. S. Adipose tissue as a endocrine organ. The Journal of Endocrinology \& Metabolism, v. 89, n. 6, p. 2548-2556, 2004. 
KIM, J.B.; SPIEGELMAN, B.M. ADD1/SREBP1 promotes adipocyte differentiation and gene expression linked to fatty acid metabolism. Genes \& Development, v.10, n. 9, p. 1096-1102, 1996.

KIM, J.K.; GAVRILOVA, K.; CHEN, Y.; REITMAN, M.L., SHULMAN, G.I. Mechanism of Insulin Resistance in A-ZIP/F-1 Fatless Mice. J. Biol. Chem., v. 275, n. 12, p. 8456-8460, 2000.

KRITCHEVSKY, D. Antimutagenic and some other effects of conjugated linoleic acid. British Journal of Nutrition, v. 83, n.5, p. 459-465, 2000.

KOPELMAN, P.G., ALBON, L. Obseity, non-insulin-dependent diabetes mellitus and the metabolic syndrome. British Medical Bulletin, v.53, n.2, p. 322-340, 1997.

LARSEN, M. T.; TOUBRO, S.; ASTRUP, A. Efficacy and safety of dietary supplements containing conjugated linoleic acid (CLA) for the treatment of obesity: evidence from animal and human studies. Journal of Lipid Research, v. 44, p. 2234-2241, 2003.

LAURINCOVÁ, B. Interleukin-1 family: from genes to human disease. Acta. Univ. Palacki. Olomuc. Fac. Med., v. 143, p. 19-29, 2000.

LEE, K. N.; PARIZA, M. W.; NTAMBI, J. M. Conjugated Linoleic Acid Decreases Hepatic Stearoyl-CoA Desaturase mRNA Expression. Biochemical and Biophysical Research Communications, v. 248, n. 3, p. 817-821, 1998.

LEHNINGER, A.L.; NELSON, D.L.; COX, M.M. Principios da Bioquímica: Lipídeos. São Paulo: Editora Sarvier, 1998, p. 179-199.

LIMA, F.B.; MATSUSHITA, D.H.; HELL, N.S.; DOLNIKOFF, M.S.; OKAMOTO, M.M.; CIPOLLA-NETO, J. The regulation of insulin action in isolated adipocytes. Role of periodicity of food intake, time of the day and melatonin. Braz. J. Med. Res, v. 27, p. 995-1000, 1994.

LIN, X.; LOOR, J.J.; HERBEIN, J.H. Trans10,cis12-18:2 Is a More Potent Inhibitor of De Novo Fatty Acid Synthesis and Desaturation than cis9,trans11-18:2 in the Mammary Gland of Lactating Mice. Jounal of Nutrition, v. 134, n. 6, p. 13621368, 2004.

LUPI, R.; DOTTA, F.; MARSELLI, F.; DEL GUERRA, S.; MASINI, M.; SANTANGELO. Prolonged exposure to free fatty acids has cystotatic and proapoptotic effects on human pancreatic islets: evedence that beta cell death is caspase mediated, partially dependent on ceramide pathway, and $\mathrm{Bcl}-2$ regulated. Diabetes, v. 51, p. 1437-1442, 2002. 
MARZZOCO, A.; TORRES, B.B. Metabolismo de lipídeos. In: Bioquímica Básica. Guanabara Koogan, Rio de Janeiro, 2 ed, p. 203, 1999.

MEDINA, E. A.; Horn, W. F.; Keim, N. L.; HAVEL, P. J.; BENITO, P.; KELLEY, D. S.; NELSON, G. J.; ERICKSON, K. L. Conjugated linoleic acid supplementation in humans: effects on circulating leptin concentrations and appetite. Lipids, v. 35, n. 7, p. 783-788, 2000.

MINER, J. L.; CEDERBERG, C. A.; NIELSEN, M. K.; BAILE, C. A. Conjugated Linoleic Acid (CLA), Body Fat, and Apoptosis. Obesity research, v. 9, p. 129-134, 2001.

NADERALI, E. K.; ESTADELLA, D.; ROCHA, M.; PICKAVANCE, L. C.; FATANI, S.; DENIS, R. G. P.; WILLIAMS, G. A fat-enriched, glucose-enriched diet markedly attenuates adiponectin mRNA levels in rat epididymal adipose tissue. Clinical Science, v. 105, p. 403-408, 2003.

NAGAO, K. INOUE, N.; WANG, YM.; YANAGITA, T. Conjugated linoleic acid enhances plasma adiponectin level and alleviates hyperinsulinemia and hypertension in Zucker diabetic fatty (fa/fa) rats. Biochemical and Biophysical Research Communications, v. 310, n. 2, p. 562-566, 2003.

NTAMBI, J.M. et al. Loss of stearoyl-CoA desaturase-1 function protects mice against adiposity. PNAS, v. 99, n. 17, p. 11482-11486, 2002.

NTAMBI, J.M.; MIYAZAKI, M.; DOBRZYN, A. Regulation of stearoyl-CoA desaturase expression. Lipids, v. 39, n. 11, p. 1061-1065, 2004.

OSCAI, L. B.; MORÉ, P. A.; KRUSACK, L. M.; HOLLOSZY, J. O. Detailed body composition analysis on female rats subjected to a program on swimming. $\mathbf{J}$ Nutr, v. 103 , n. 3, p. 412-418, 1973.

PARIZA, M. W.; HARGRAVES, W. A. A beef-derived mutagenesis modulator inhibits initiation of mouse epidermal tumors by 7,12-dimethilbenz[a]anthracene. Carcinogenesis, v. 6, p. 591-593, 1985.

PARIZA, M. W.; PARK, Y.; COOK, M. E. Conjugated linoleic acid and the control of cancer and obesity. Toxicological Sciences, v. 52, p. 107-110, 1999.

PARIZA, M. W.; PARK, Y.; COOK, M. E. Mechanisms of Action of Conjugated Linoleic Acid: Evidence and Speculation. Proceedings of the Society for Experimental Biology and Medicine, v. 223, p. 8-13, 2000.

PARIZA, M. W.; PARK, Y.; COOK, M. E. The biologically active isomers og conjugated linoleic acid. Prog. Lipid. Res, v. 40, n. 4, p. 283-298, 2001. 
PARK, Y.; ALBRIGHT, K. J.; LIU, W.; STORKSON, J. M.; COOK, M. E.; PARIZA, M. W. Effect of conjugated linoleic acid on body composition in mice. Lipids, v. 32, n. 8, p. 853-858, 1997.

PARK, Y.; STORKSON, J.M.; ALBRIGHT, K.J.; LIU, W.; PARIZA, M.W. Evidence that the trans-10,cis-12 isomer of conjugated linoleic acid induces body composition changes in mice. Lipids, v. 34, n. 3, p. 235-241, 1999.

PARK, Y.; STORKSON, J. N.; NTAMBI, J.M.; COOK, M.E.; SIH, C. J.; PARIZA M. W. Inhibition of hepatic stearoyl-CoA desaturase activity by trans-10, cis-12 conjugated linoleic acid and its derivatives. Biochim. Biophys. Acta., v. 486, n. 23, p. 285-292, 2000.

PÉREZ-MATUTE, P.; MARTI, A.; FERNÁNDEZ-OTERO, M. P.; STANHOPE, K. L.; HAVEL, OP. J.; MORENO-ALIAGA, M. J. Conjugated linoleic acid inhibits glucose metabolis, leptin and adiponectin secretion in primary cultured rat adipocytes. Molecular and Cellular Endocrinology, v. 268, p. 50-58, 2007.

PHILIPS, D.I.W.; HIRST, S.; CLARK, P.M.S.; HALES, C.N.; OSMOND, C. Fetal growth and insulin secretion in adult life. Diabetologia, v. 37, n. 6, p. 592-596, 1994.

POIRIER, H.; NIOT, I.; CLÉMENT, L.; GUERRE-MILLO, M.; BESNARD, P. Development of conjugated linoleic acid (CLA) - mediated lipoatrophic syndrome in the mouse. Biochimie, v. 87, p. 73-79, 2004.

POIRIER, H.; ROUAULT, C.; CLÉMENT, L.; NIOT, I.; MONNOT, M.-C.; GUERREMILO, M.; BESNARD, P. Hyperinsulinaemia triggered by dietary conjugated linoleic acid is associated with a decrease in leptin and adiponectin plasma levels and pancreatic beta cell hyperplasia in the mouse. Diabetologia, v. 48, n. 6, p. 1059-1065, 2005.

POIRIER, H.; SHAPIRO, J. S.; KIM, R. J.; LAZAR, M. A. Nutritional Supplementation With trans-10, cis-12-Conjugated Linoleic Acid Induces Inflammation of White Adipose Tissue. Diabetes, v. 55, p. 134-1641, 2006.

PORTE, D.; BASKIN, D.G.; SCHWARTZ, M.W. Leptin and insulin action in the central nervous system. Nutr. Rev., v. 60, p. 68-87, 2002.

POULOS, S.P.; SISK, M.; HAUSMAN, D.B.; AZAIN, M.J.; HAUSMAN, G.J. Preand Postnatal Dietary Conjugated Linoleic Acid Alters Adipose Development, Body Weight Gain and Body Composition in Sprague-Dawley Rats. Journal of Nutrition, v. 131, n. 10, p. 2722-2731, 2001.

PRINS, J. B. Adipose tissue as an endocrine organ. Best Practice \& Research Clinical Endocrinology and metabolism, v. 16, n. 4, p.639-651, 2002. 
RAHMAN, S. M.; WANG, Y.; YOTSUMOTO, H.; CHA, J.; HAN. S.; INOUE, S.; YANAGITA, T. Effects of conjugated linoleic acid on serum leptin concentration, body-fat accumulation, and beta-oxidation of fatty acid in OLETF rats. Nutrition, v. 17, n. 5 , p. 385-390, 2001.

RAINER, L.; HEISS, C. J.; Conjugated linoleic acid: health implications and effects on body composition. J. Am. Diet. Assoc., v. 104, n. 6, p. 963-968, 2004.

ROCHE, H.M.; NOONE, E.; NUGENT, A.; GIBNEY, M.J. Conjugated linoleic acid: a novel theraputic nutrient? Nutr Res Rev, v. 14, p. 173-187, 2001.

RODBELL M. Metabolism of isolated fat cells. Effects of hormones on glucose metabolism and lipids. J. Biol. Chem., v. 239, p. 357-380, 1964.

RYDER, J.W.; PORTOCARRERO, C. P.; SONG, X.M.; CUI, L.; YU, M.; COMBATSIARIS, T.; ZIERATH, J. R.; HOUSEKNECHT, K. L. Isomer specific antidiabetic properties of conjugated linoleic acid. Diabetes, v. 50, p. 1149-1157, 2001.

SALAS-SALVADÓ, J.; MÁRQUES-SANDOVAL, F.; BULLÓ, M. Conjugated linoleic acid intake in humans: A systematic review focusing on its effect on body composition, glucose, and lipid metabolism. Critical Reviews in Food Science and Nutrition, v. 46, p. 479-499, 2006.

SARTIPY, P.; LOSKUTOFF, D.J. Monocyte chemoattractant protein 1 in obesity and insulin resistance. Proceedings of the National Academy of Sciences, v. 100, n. 12, p. 7265-7270, 2003.

SEAQUIST, E.R.; KAHN, S.E.; CLARCK, P.M.; HALES, N.; PORTE, D.; ROBERTSON, P.R. Hyperproinsulinemia Is Associated with Increased B Cell Demand after Hemipancreatectomy in Humans. J. Clin. Invest., v. 97, n. 2, p. 455460, 1996.

SHOELSON, E.S.; LEE, J.; GOLDFINE, A.B. Inflammation and insulin resistance. J Clin Invest., v.116, n.7, p. 1783-1801, 2006.

SCHWARTZ, M.W.; SIPOLS, A.J.; MARKS, J.L.; SANACORA, G.; WHITE, J.D.; SCHEURINK, A.; KAHN, S.E.; BASKIN, D.G.; WOODS, S.C.; FIGLEWICZ, D.P. Inhibition of hypothalamic neuropeptide $Y$ gene expression by insulin. Endocrinology, v. 130, p. 3608-3616, 1992.

SHWARTZ, M.W.; WOODS, S.C.; PORTE, D.J.; SEELEY, R.J.; BASKIN, D.G. Central nervous system control of food intake. Nature, v. 404, p. 661-671, 2000.

SIMON, E.; MACARULLA, M. T.; FERNADEZ-QUINTELA, A.; RODRIGUES, V.M.; PORTILLO, M. P. Body fat-lowering effect of conjugated linoleic acid is not due to increased lipolysis. J. Physiol. Biochem., v. 61, n. 2, p. 363-369, 2005. 
SISK, M. B.; HAUSMAN, D. B.; MARTIN, R. J.; AZAIN, M. J. Dietary Conjugated Linoleic Acid Reduces Adiposity in Lean but Not Obese Zucker Rats. Journal of Nutrition, v. 131, p. 1668-1674, 2001.

TAKAHASHI, Y.; KUSHIRO, M.; SHINOHARA, K.; IDE, T. Dietary conjugated linoleic acid reduces body fat mass and affects gene expression of proteins regulating energy metabolism in mice. Comp Biochem. Physiol. B. Biochem. Mol. Biol., v. 133, n. 3, p. 395-404, 2002.

TONTONOZ, P.; HU, E.; SPIEGELMAN, B.M. Stimulation of adipogenesis in fibroblasts by PPAR gamma 2, a lipid-activated transcription factor. Cell, v. 79, n. 7, p. 1147-1156, 1994.

TSUBOYAMA-KASAOKA, N.; TAKAHASHI, M.; TANEMURA, K.; KIM, H-J.; TANGE, T.; OKUYAMA, H.; KASAI, M.; IKEMOTO, S.; EZAKI, O. Conjugated linoleic acid supplementation reduces adipose tissue by apoptosis and develops lipodistrophy in mice. Diabetes, v. 49, p. 1534-1542, 2000.

WANG, Y.; JONES, P. J. H. Dietary conjugated linoleic acid and body composition. Am J. Clin. Nutr., v. 79, p. 1153S-1158S, 2004

WEST, D. B.; BIOHM, F. Y.; TRUETT, A. A.; DELANY, J. P. Conjugated linoleic acid persistently increases total expenditure in AKR/J mice increasing uncoupling protein gene expression. Journal of Nutrition, v. 130, p. 2471-2477, 2000.

WEST, D. B.; DELANY, J. P.; CAMET, P. M.; BLOHM, F.; TRUETT, A. A.; SCIMECA, J. Effects of conjugated linileic acid on body fat and energy metabolism in the mouse. American Physiological Society, p. 667-672, 1998.

WEST, D.B.; BLOHM, F.Y.; TRUETT, A.A.; DELANY, J.P. Conjugated Linoleic Acid Persistently Increases Total Energy Expenditure in AKR/J Mice without Increasing Uncoupling Protein Gene Expression. Journal of nutrition. v. 130, n. 10 , p. $2471-2477,2000$.

WILDING, J. P. H. The importance of free fatty acids in the development of type 2 diabetes. Diabetic Medicine, v. 24, p. 934-945, 2007.

WOODS, S.C.; LOTTER, E.C.; MCKAY, L.D.; PORTE, D.J. Chronic intracerebroventricular infusion of insulin reduces food intake and body weight of baboons. Nature, v. 282, p. 503-505, 1979.

WOODS, S.C.; SEELEY, R.J.; PORTE, D.; SCHWARTZ, M.W. Signals That Regulate Food Intake and Energy Homeostasis. Science, v. 280, n. 5368, p. 13781383, 1998. 
YAMAUSHI, T. et al. The fat-derived hormone adiponectin reverses insulin resistance associated with both lipoatrophy and obesity. Nature Medicine, v. 7, p. 941-946, 2001.

ZABALA, A.; PORTILLO, M.P.; MACARULLA, M.T.; RODRIGUES, V.M.; FERNÁNDES-QUINTELA, A. Effects of cis-9, trans-11 and trans-10, cis-12 CLA isomers on liver and adipose tissue fatty acid profile in hamsters. Lipids, v. 41, n. 11, p. 993-1001, 2006. 
